NBER WORKING PAPER SERIES

\title{
THE RULES OF STANDARD SETTING ORGANIZATIONS: AN EMPIRICAL ANALYSIS
}

\author{
Benjamin Chiao \\ Josh Lerner \\ Jean Tirole \\ Working Paper 11156 \\ http://www.nber.org/papers/w11156 \\ NATIONAL BUREAU OF ECONOMIC RESEARCH \\ 1050 Massachusetts Avenue \\ Cambridge, MA 02138 \\ February 2005
}

Harvard Business School and the National Science Foundation provided financial support. We thank seminar participants at the Federal Reserve Bank of Chicago/Kellogg "Standards and Public Policy" conference, Melbourne Business School, and the IDEI Conference on the Economics of the Internet and Software Industries for helpful comments, as well as Ken Krechmer, Mark Lemley, and Halla Yang. Research support was provided by Aurora Bryant, Vicky Chang, Seung-ju Paik, Mimi Tam, and Olga Trzebinska. All errors are our own.The views expressed herein are those of the author(s) and do not necessarily reflect the views of the National Bureau of Economic Research.

(C) 2005 by Benjamin Chiao, Josh Lerner, and Jean Tirole. All rights reserved. Short sections of text, not to exceed two paragraphs, may be quoted without explicit permission provided that full credit, including $($ ) notice, is given to the source. 
The Rules of Standard Setting Organizations: An Empirical Analysis

Benjamin Chiao, Josh Lerner, and Jean Tirole

NBER Working Paper No. 11156

February 2005

JEL No. L2, O3

\section{ABSTRACT}

This paper empirically explores the procedures employed by standard-setting organizations. Consistent with Lerner-Tirole (2004), we find (a) a negative relationship between the extent to which an SSO is oriented to technology sponsors and the concession level required of sponsors and (b) a positive correlation between the sponsor-friendliness of the selected SSO and the quality of the standard. We also develop and test two extensions of the earlier model: the presence of provisions mandating royalty-free licensing is negatively associated with disclosure requirements, and when there are only a limited number of SSOs, the relationship between concessions and user friendliness is weaker.

Benjamin Chiao

School of Information North

1075 Beal Avenue

University of Michigan

Ann Arbor, MI 48109-2112

benjamin.chiao@gmail.com

Josh Lerner

Rock Center for Entrepreneurship

Harvard Business School

Boston, MA 02163

and NBER

josh@hbs.edu

Jean Tirole

Institut d' Economie Industrielle

Manufacture des Tabacs

Bureau MF529 - Bat. F

21 allees de Brienne

31000 Toulouse France

tirole@cict.fr 


\section{Introduction}

The economic importance of technological standards has grown tremendously over the past two decades. The growing recognition of the importance of the standardization process has been attributed in large part to the growth of the information technology and communications industries, for which standards are critical. At the same time, there has been substantial flux among these organizations: for instance, over the past 15 years, consortia and informal standard-setting bodies have in many cases supplanted formal national and international standard development organizations (Cargill (2002)).

Yet despite this growing and dynamic economic role, standard-setting organizations (SSOs) have attracted remarkably little empirical attention from economists. This paper seeks to address this gap by investigating the relationship between these organizations' characteristics and their policies governing the disclosure and licensing of intellectual property such as patent awards.

To frame our empirical analysis, we first highlight some of the implications of the baseline model in Lerner and Tirole (2004). In particular, we highlight that the extent of concessions made by technology sponsors will be positively correlated with the userfriendliness of the SSO (defined as the relative weight of users over sponsors in the SSO's objective function) and that when a standard is more desirable (which we anticipate will be associated with the maturity of the technology), a less user-friendly SSO will be selected.

We then extend this model in two ways. First, we consider requirements around disclosure. From the theoretical analysis emerges the prediction that within an equilibrium, a higher licensing price is associated with more disclosure. Second, we examine settings in which there are only a limited number of SSOs, and hence these organizations can dictate terms to technology sponsors. We show that in settings where there are only a limited number of SSOs, the relationship between concessions and user friendliness is unlikely to hold: sponsor-friendly SSOs are tempted to demand substantial concessions to provide certification and therefore attract weak standards; by contrast, user-friendly SSOs are tempted to make weak demands so as to appeal to sponsors with stronger technologies.

To address these questions, we built the first database of SSOs sufficiently large to enable cross-sectional analyses. Combining information from the SSOs' web sites, records of standards bodies, and information collected from surveys and interviews, we compiled a database of nearly 60 bodies.

Our results are largely consistent with our theoretical suggestions. We find a negative relationship between the extent to which a standard setting organization is oriented towards sponsors and the concessions required of the technology sponsors. Second, sponsor orientation of the selected SSO is positively associated with the maturity of a technological field of the standard. 
The results are also largely consistent with the theoretical extensions developed in this paper. First, we find that the presence of a provision mandating royalty-free licensing is negatively associated with the presence of a disclosure requirement, while weaker "reasonable" licensing requirements are strongly associated with such a provision. Second, when we divide the SSOs into those with above and below the median number of other SSOs in their technological sub-field, we find that the relationship between user friendliness and concessions is considerably tighter among SSOs located in classes with many other organizations.

The plan of this paper is as follows. Section 2 reviews the related literature. Section 3 presents the theoretical frame for our analysis. The data are discussed in Section 4. Section 5 presents the analysis. The final section concludes the paper.

\section{Related Literature}

Despite the copious research on standards, it is striking how little work has addressed the question of how these organizations are or should be organized. Many of the papers in the literature focus only on de facto standard setting, where there is no role for an SSO in the model (e.g., Farrell and Saloner (1985)). Alternatively, a number of works, both in economics and political science, have focused on settings where government bodies have played the key role in adjudicating between the desires of different parties about possible standards (e.g., Farrell and Shapiro (1992)). In addition, several papers have considered which settings (e.g., the extent of buyer and seller concentration and product differentiation) are suited to the establishment of standards (for instance, Hemenway (1975)). Finally, in recent years papers have examined the interaction between SSO's intellectual property rules and antitrust considerations. ${ }^{1}$

The work in the economics literature that has focused on the institution of SSOs has largely focused on just one role: that of a forum where competitors can resolve conflicts. In Farrell and Saloner (1988), two firms can choose between two incompatible technologies. They can do so by repeatedly talking with each other (seen as akin to an $\mathrm{SSO}$ ), by product market competition (de facto standard setting in the marketplace), or a hybrid between the two approaches. The SSO in their model is a place where the two parties can negotiate, but has no institutional features (e.g., rules governing decisionmaking or requiring concessions from sponsors). Nor would there be a need for more than one SSO in this setting, since the features of the SSO do not matter. The authors show that the committee process is more likely to arrive at a high-value consensus than product market competition, but that it usually takes longer. The hybrid approach is likely to dominate both of the alternatives.

Farrell (1996) models the standard-setting process as a "war of attrition" between two parties with their own proposed standard. The various participants receive a larger share

\footnotetext{
${ }^{1}$ Besen and Saloner (1989) discuss non-governmental SSOs, but they focus their more analytic discussions-whether entailing the development of new theory or narratives that attempt to relate institutional features to theory-on de facto standard-setting activity.
} 
of the profits if their own standard is selected, which depend on the (privately known) quality of the standard selected. He shows that ultimately, the higher-quality technology will be selected, but that the delays will be a function of the presence of vested interests. Reducing vested interests (e.g., by adopting rules that limit the utilization of intellectual property used in standards) will reduce delays. Simcoe (2003) similarly depicts the standard-setting process as a "war of attrition" between multiple parties, each with their own proposed standard. While the highest quality project ends up being selected, the time to this selection will vary with the size of the distortions introduced by the uneven distribution of the surplus and the benefits from coordinating with each other. He then seeks to corroborate the model using standards considered by the Internet Engineering Task Force.

Aside from Simcoe's work, however, empirical work on SSOs has been dominated by case studies. Sirbu and Zwimpfer (1985) present a case study of X.25, which standardized "packet switching" over public networks. Besen and Johnson (1986) examine seven cases where SSOs reached consensus on broadcast standards. Weiss and Sirbu (1990) examine eleven choices between proposed standards made by standardsetting bodies.

\section{The Theory}

\subsection{Concessions under free SSO entry}

In Lerner and Tirole (2004), we explored a setting where the owner of an idea or property must convince potential users of its value. We highlighted the important role that intermediaries offering (at least somewhat) independent certification can play in the process.

In particular, we assumed that the utility of the users of the technology considered by the SSO were $U=a+b+c$, where:

- $\quad a$ is common knowledge and measures the strength of the proposed standard.

- $\quad b$ is unknown to both technology sponsor and users and reflects unobserved quality to users.

- $\quad c$ is the extent of concessions made to users: e.g., requirements to license intellectual property critical to the standard.

We assume that users will adopt the standard only if $U$ appears to be positive.

The SSO has an objective function which weights the benefits accruing to the users and that of the technology sponsor, $U+\alpha \pi$. In this setting, $\alpha$ is the weighting factor, or (the opposite of) user-friendliness. In our basic model, we assume free entry for SSOs, so there is a continuum of SSOs with different levels of user-friendliness. $\pi$, the sponsor's profit, is a decreasing function of $c: \pi^{\prime}(c)<0$ and $\pi^{\prime \prime}(c) \leq 0$. 
Let $F(b)$ denotes the cumulative distribution function. We assume that $F$ has the standard monotone hazard rate property: $f /[1-F]$ is increasing. This property in turn implies that $m(b) \equiv E[\tilde{b} \mid \tilde{b} \geq b]$ grows with $b$ at a rate lower than 1 . Furthermore:

$$
m^{\prime}(b) \equiv \frac{f(b)}{1-F(b)}[m(b)-b]
$$

Timing. We consider the following three-stage game:

(1) The sponsor chooses an SSO, that is $\alpha$, and a concession $c$.

(2) The SSO learns $b$ (more generally, it could learn a signal of $b$ ), and then chooses whether to recommend the standard.

(3) Users decide whether to adopt the standard.

Formally, the concession $c$ is chosen by the sponsor. However condition (3) below implies that $c$ could alternatively be selected by the SSO, that is, under free SSO entry there is no dissonance between the sponsor and the selected SSO with regards to the choice of concession. ${ }^{2}$

The SSO with type $\alpha$ endorses the standard if and only if

$$
[a+b+c]+\alpha[\pi(c)] \geq 0
$$

The standard is therefore adopted by the users following an endorsement by the SSO if and only if:

$$
a+E[b \mid b \geq-(a+c+\alpha \pi(c))]+c \geq 0
$$

The sponsor then solves

$$
\max _{\{\alpha, c\}}[1-F(-(a+c+\alpha \pi(c)))] \pi(c)
$$

subject to (1). Condition (1), satisfied with equality, defines $\alpha$ for a given choice of $c$ :

$$
b^{*} \equiv-[a+c+\alpha \pi(c)]=m^{-1}(-(a+c))
$$

Thus, the maximization can be rewritten as:

$$
\max _{\{c\}}\left[1-F\left(m^{-1}(-(a+c))\right)\right] \pi(c),
$$

\footnotetext{
${ }^{2}$ It can further be shown that nothing would change if $c$ were chosen after the SSO endorses the standard and before the users adopt the technology (see Lerner-Tirole 2004).
} 
or

$$
\max _{\{c\}}\left\{\log \left[1-F\left(m^{-1}(-(a+c))\right)\right]+\log \pi(c)\right\}
$$

This latter objective function is concave. Taking its derivative and using the expression of $m^{\prime}$ :

$$
\frac{1}{m\left(b^{*}\right)-b^{*}}+\frac{\pi^{\prime}(c)}{\pi(c)}=0
$$

where

$$
b^{*} \equiv m^{-1}(-(a+c))
$$

Furthermore, equation (2), together with the identities $a+m\left(b^{*}\right)+c=0$ and $a+b^{*}+c+\alpha \pi=0$, yields:

$$
1+\alpha \pi^{\prime}(c)=0
$$

Proposition 1 (Lerner-Tirole 2004) (i) The equilibrium concession is given by

$$
\frac{1}{m\left(b^{*}\right)-b^{*}}=\frac{-\pi^{\prime}(c)}{\pi(c)}, \text { where } b^{*}=m^{-1}(-(a+c)) \text {. }
$$

(ii) The weaker the proposed standard, the more extensive the concessions and the more credible the SSO selected by the sponsor: $c^{*}$ decreases with a and $\alpha^{*}$ increases with $a$.

Two key empirical predictions come out of this analysis:

- The extent of concessions will be positively correlated with the user-friendliness of the organization ( $c$ and $\alpha$ will be negatively correlated).

- When the standard has a higher $a$, or is more desirable (which we anticipate will be associated with the maturity of the technology), the $\alpha$ of the selected organization will be higher.

Note, finally, that when concessions are (minus the level of) royalties, i.e., $\pi=\pi_{0}+p$ and $c=-p$, the optimal $\alpha$ is equal to 1 .

\subsection{Determinants of disclosure}

One aspect that we did not consider in the earlier paper is disclosure. In our interviews, firms highlighted several costs associated with the disclosure of information in the standard setting process, even of already-issued patents. In particular, they argued that due to the number and complexity of patent portfolios, rivals frequently could not 
determine "the needle in the haystack": that is, which patents were relevant to a given standardization effort. ${ }^{3}$ By highlighting the relevant patents or applications, in many cases firms felt they were disclosing valuable information to competitors about the applicability of their patent portfolios and their future technological strategies more generally. Second, early disclosure of plans may invalidate the ability to get future awards. Third, the undisclosed intellectual property may have multiple uses, one of them relative to the standard. A disclosure can spur efforts to invent around the technologies and thereby either lead to a sacrifice in profits in unrelated markets, or else boost the attractiveness of a competing standard. In such cases, the sponsor would like to retain secrecy—or at least ambiguity—of the applicability of its patent portfolio.

Some SSOs demand that sponsors commit to revealing awards and/or applications shortly before the standard is endorsed. Others do not require disclosure, although there is an understanding that undisclosed patents that are later deemed relevant to the standard will be subject to the same pricing principles as the ones that are currently examined by the SSO: for example, a royalty-free agreement will as well cover undisclosed, essential patents in the future. While in our sample, the same pricing regime (for instance, royaltyfree or reasonable-and-non-discriminatory (RAND)) applies to both disclosed and undisclosed patents, it is not a priori obvious why this is the case. In particular a sponsor who does not wish to disclose patent applications, wants to collect royalties on examined patents, and yet would like to reassure users as to the possibility of a hold-up, could offer RAND on patents disclosed in advance of the adoption of a standard, and a royalty-free treatment for undisclosed patents that are subsequently deemed essential. ${ }^{4}$

Intuitively, disclosure involves a trade-off between reassuring users and not wasting intellectual property. On the one hand, the absence of disclosure raises the concern that users, once they have invested in the technology, will be held up by the sponsor as a missing piece of intellectual property is needed for the most effective implementation of the technology. On the other hand, in the absence of hold-up concerns of the users, the sponsor would prefer not to disclose applications or technological strategies more generally.

In order to investigate the relationship between disclosure policies, pricing and userfriendliness, let us study the following extension of the basic model. The sponsor has two pieces of intellectual property:

- the existing, disclosed patent (or set of patents), that forms the basis for the standard;

- an "add-on" potential patent, that is subject to an application to the patent office or is merely in the pipeline. There is no uncertainty about whether the patent on this addon will be granted (nothing changes if the patent will be granted with probability less

\footnotetext{
${ }^{3}$ In fact, U.S. legal rules mandating trebled damages for willful infringement lead firms to discourage their engineers from even examining the patent portfolios of their competitors.

${ }^{4}$ Indeed, such a "mixed regime" has been proposed under the name of "penalty default" by Lemley (2002).
} 
than 1).

There are two states of nature, i.e., two types of sponsors: "good" (probability $\rho$ ) and "bad" (probability $1-\rho$ ). In either case, the add-on patent adds value $H$ to the standard. What differs is the baseline value. For the good type, the add-on really adds to the value of the existing technology: the attractiveness parameter increases from $a$ to $a+H$. By contrast, for the bad type, the add-on is a missing piece in the initial standard. In its absence, the proposed standard has attractiveness $a-H$ only, and what the add-on does is to restore this attractiveness parameter to its full-implementation value $a$. Thus, $H$ is a measure of the potential for hold-up.

The timing goes as follows:

(i) The sponsor applies to an SSO with parameter $\alpha$. The application specifies whether patent applications are to be disclosed (D) or not (ND) upon acceptance. It also specifies prices, $p \geq 0$ for the basic technology and $q \in[0, H]$ for the add-on.

(ii) The SSO observes $b$, and under disclosure the state of nature; it then chooses to endorse the technology or not. If the technology is endorsed and under a disclosure agreement (D), the sponsor must disclose the add-on.

(iii) The users choose whether to adopt the technology and, if so, pay price $p$.

(iv) The sponsor receives a patent for the add-on, which is then deemed essential by the SSO (if it has not been disclosed earlier) and proposes a price $q$ to the users.

The good type incurs disclosure cost $d>0$ in unrelated markets, say, when the add-on is disclosed (the disclosure cost for the bad type is irrelevant as long as it is strictly positive, since the bad type then never has an incentive to disclose). Disclosure of the add-on reveals whether the add-on is a true improvement or else just implementation-enabling.

A couple of important points are in order. First, the sponsor cannot do better than choosing to contract on whether to disclosure and prices (the contract is an optimal one). Because the value added by the add-on patent is the same, $H$, in both states of nature, it is not possible to elicit from users information about the state of nature. Second, we implicitly assume that the sponsor cannot disclose to the SSO confidentially, i.e., that the disclosure is subject to leakages. Otherwise, disclosure would always be a dominant strategy for the good type (and costless for the bad type). It would just not be perceived as costly and would be a non-issue. ${ }^{5}$

\footnotetext{
${ }^{5}$ The reader may wonder how the SSO can decide to endorse the standard before seeing the add-on in case the policy is one of disclosure. This, however, is not an issue. Because only the good type may in equilibrium disclose, the SSO can presume that the basic technology has value $a$ and accept conditionally on checking that this is indeed correct. Mathematically it endorses the standard if and only if

$$
[(a+H)+b-(p+q)]+\alpha\left[\pi_{0}+(p+q)\right] \geq 0,
$$

and commits not to endorse the technology if the basic value is $a-H$ rather than the claimed level of $a$.
} 
The game is a signaling game. As will become clear from the expressions of profits, the good and bad types have the same preferences over prices $p$ and $q$. Thus, we assume that the SSO and the users infer nothing about the state of nature from the choice of $p$ and $q$. By contrast, preferences differ as to the disclosure decision, which therefore will convey information to the SSO and the users. Second, we will show that the signaling game always has a Pareto-dominant equilibrium; we will accordingly focus on this equilibrium for comparative statics purposes.

\section{(a) Disclosure}

As we noted, only the good type can benefit from disclosure. Letting $b^{*}$ denotes the SSO's cut-off, and $\left(p^{D}+q^{D}\right)$ the proposed prices, users adopt the technology if and only if:

$$
(a+H)+m\left(b^{*}\right)-\left(p^{D}+q^{D}\right) \geq 0 .
$$

Letting $P^{D} \equiv p^{D}+q^{D} \geq 0$, the sponsor's expected profit is

$$
\left[1-F\left(b^{*}\right)\right]\left[\pi_{0}+P^{D}-d\right]
$$

accounting for the fact that the disclosure cost $d$ is incurred only in case of endorsement, as is the case in practice. (Note, too, that such conditional acceptance maximizes the SSO's appeal, as it avoids wasteful disclosure in cases in which the standard would be turned down, that is, when $b<b^{*}$.)

And so the good type's profit under disclosure is:

$$
\left.\left.\pi^{D}(d, a)=\underset{\left\{b^{*} \mid b^{*} \geq m^{-1}(-(a+H))\right\}}{\max }\left\{1-F\left(b^{*}\right)\right] \mid \pi_{0}+(a+H)+m\left(b^{*}\right)-d\right]\right\},
$$

where the set restriction refers to the constraint that the price $P^{D}$ be non-negative. ${ }^{6}$

\section{(b) Nondisclosure}

Let $\hat{\rho}$ denotes the SSO's and the users' posterior probability of the sponsor being of the good type when there is no disclosure:

\footnotetext{
${ }^{6}$ If at the optimum $P^{D}>0$, then there is an indeterminacy as to the respective levels of $p^{D}$ and $q^{D}$ (as long as $p^{D}+q^{D}=P^{D}$ and $q^{D} \leq H$ ). If there were a cost of developing the add-on, arbitrarily small in expectation, but with wide support, the optimal contract would backload payments through a two-part tariff with $q^{D}=\min \left\{P^{D}, H\right\}$, so as to provide the sponsor with maximal incentives to develop the add-on. The indeterminacy would be removed.
} 
$0 \leq \hat{\rho} \leq \rho$.

Letting $\quad P^{N D} \equiv p^{N D}+q^{N D}$, and letting $\hat{b}$ denote the SSO's cut-off, users adopt the standard if and only if:

$$
(a+\hat{\rho} H)+m(\hat{b})-P^{N D} \geq 0
$$

The sponsor's expected profit in the absence of disclosure is type-independent and equal to:

$$
\pi^{N D}(\hat{\rho}, a)=\max _{\left\{\hat{b} \hat{b} \geq m^{-1}(-(a+\hat{\rho} H))\right\}}\left\{\left[1-F(\hat{b}) \|\left[\pi_{0}+(a+\hat{\rho} H)+m(\hat{b})\right)\right\} .\right.
$$

A separating equilibrium exists if and only if

$$
\pi^{D}(d, a) \geq \pi^{N D}(0, a)
$$

A pooling equilibrium exists if and only if

$$
\pi^{N D}(\rho, a) \geq \pi^{D}(d, a)
$$

Finally, a semi-separating equilibrium exists if there exists $\hat{\rho} \in(0, \rho)$ such that

$$
\pi^{D}(d, a)=\pi^{N D}(\hat{\rho}, a)
$$

Lemma 1 ( $i$ ) If multiple equilibria co-exist, both types of sponsor are better off in the one with the least amount of disclosure (the maximal amount of pooling). Furthermore, either the separating equilibrium exists and is unique, or the Pareto-dominant equilibrium is the pooling equilibrium.

(ii) [Focusing on the Pareto-dominant equilibrium in case of multiplicity], there exists $d^{*}>0$ such that separation obtains for $d<d^{*}$ and pooling for $d \geq d^{*}$.

Proof: (i) $\pi^{D}$ is belief-free. By contrast, the two types' (common) payoff in the absence of disclosure is increasing in $\hat{\rho}$. And so both prefer $\hat{\rho}$ to be equal to $\rho$. More formally, either $\pi^{D}(d, a)>\pi^{N D}(\rho, a)$ and then the equilibrium is unique and separating. Or $\pi^{D}(d, a) \leq \pi^{N D}(\rho, a)$ and then the pooling equilibrium exists and dominates any other equilibrium.

(ii) This results from the fact that $\pi^{D}$ is decreasing in $d$, while $\pi^{N D}$ does not depend on $d$. 
From now on, we will select the Pareto-dominant pooling equilibrium when it exists (when it does not, the separating equilibrium is the only equilibrium anyway).

\section{Proposition 2 (within equilibrium: disclosure positively correlated with $(\alpha, P)$ )}

In (a separating) equilibrium, disclosure is associated with a) higher prices and b) lower user-friendliness of the selected SSO.

Note that we focus on separating equilibria. There is no variation if pooling obtains.

Proof: $\quad$ Compare the two programs

$$
\left.\pi^{D}(d, a)=\underset{\left\{b^{*} \mid b^{*} \geq m^{-1}(-(a+H))\right\}}{\max }\left\{1-F\left(b^{*}\right)\right]\left[\pi_{0}+(a+H)+m\left(b^{*}\right)-d\right]\right\},
$$

and

$$
\pi^{N D}(0, a)=\max _{\left\{\hat{b} \mid \hat{b} \geq m^{-1}(-a)\right\}}\left\{1-F(\hat{b}) \|\left[\pi_{0}+a+m(\hat{b})\right]\right\}
$$

a) Let us first demonstrate that disclosure is associated with a higher price in a separating equilibrium. Let us assume a contrario that $P^{N D}>P^{D}$. This inequality can arise only if $P^{N D}>0$. In this case, the set restriction in the maximization giving $\pi^{N D}$ is not binding. Suppose, first, that $H<d$. Then, the maximand in $\pi^{N D}$ exceeds that in $\pi^{D}$ for any value of the cut-off. Using the quasi-concavity of the objective functions, we conclude that $\pi^{N D}>\pi^{D}$, which contradicts the existence of a separating equilibrium. And so $P^{N D}>0 \Rightarrow H \geq d$.

Because $P^{N D}>0$, then $\alpha^{N D}=1$ and so the cut-off $\hat{b}$ is the efficient cut-off. By contrast, $\alpha^{D} \leq 1$ (with equality if $P^{D}>0$ ) and so the cut-off $b^{*}$ is either efficient or socially too high. Thus we have:

$$
\left\lfloor(a+H)+b^{*}\right\rfloor+\left[\pi_{0}-d\right] \geq 0
$$

and

$$
[a+\hat{b}]+\pi_{0}=0
$$

And so

$$
P^{D}-P^{N D}=\left[a+H+m\left(b^{*}\right)\right]-\lfloor a+m(\hat{b})\rfloor
$$


or using the fact that $m^{\prime}<1$,

$$
=H-\left\lfloor m(\hat{b})-m\left(b^{*}\right)\right\rfloor
$$

$$
P^{D}-P^{N D}>d>0
$$

Thus, the non-negativity constraint is indeed non-binding for $P^{D}$, and we obtain the result that $P^{D} \geq P^{N D}$.

b) Let us finally show that $\alpha^{D} \geq \alpha^{N D}$. This is clearly the case when $P^{D}>0$, as then $\alpha^{D}=1$ and $\alpha^{N D} \leq 1$. So, assume that $P^{D}=P^{N D}=0$. Using the users' and the SSO's indifference equations, one then gets:

$$
a+H+m\left(b^{*}\right)=a+m(\hat{b})=0
$$

and

$$
(a+H)+b^{*}+\alpha^{D}\left[\pi_{0}-d\right]=a+\hat{b}+\alpha^{N D} \pi_{0}=0
$$

implying that

$$
\left(\alpha^{D}-\alpha^{N D}\right) \pi_{0}=\left[m\left(b^{*}\right)-b^{*}\right]-[m(\hat{b})-\hat{b}]+\alpha^{D} d,
$$

which together with $m^{\prime}<1$ and $b^{*}>\hat{b}$ yields

$$
\alpha^{D}>\alpha^{N D} \text {. }
$$

\section{Proposition 3 (disclosure is less likely for an attractive standard)}

When the technology becomes less attractive ( a falls), the range of disclosure costs for which disclosure occurs in equilibrium expands ( $d^{*}$ grows).

Proof: Recall that $d^{*}$ is given by

$$
\pi^{D}\left(d^{*}, a\right)=\pi^{N D}(\rho, a)
$$

Let $P^{D}$ and $P^{N D}$ denote the prices under disclosure and non-disclosure and pooling (beware that $P^{N D}$ is not the same as in the previous proposition, as we are now looking at pooling rather than separating. By the same proof, though, with the relevant comparison being $H(1-\rho){ }_{<}^{>} d$ rather than $\left.H_{<}^{>} d, P^{D} \geq P^{N D}\right)$.

Suppose, first, that $P^{D}=P^{N D}=0$. Then, for $d=d^{*}$, 


$$
\left\lfloor 1-F\left(m^{-1}(-a-H)\right)\right\rfloor\left(\pi_{0}-d^{*}\right)=\left\lfloor 1-F\left(m^{-1}(-a-\rho H)\right)\right\rfloor \pi_{0}
$$

and

$$
\frac{\partial\left(\pi^{N D}-\pi^{D}\right)}{\partial a}=\frac{1-F(\hat{b})}{m(\hat{b})-\hat{b}} \pi_{0}-\frac{1-F\left(b^{*}\right)}{m\left(b^{*}\right)-b^{*}}\left(\pi_{0}-d\right)
$$

(using the fact that $m^{\prime}=\frac{f}{1-F}(m-b)$ ). Because $[m(b)-b] /(1-F(b))$ is decreasing and $\hat{b}>b^{*}$,

$$
\frac{\partial\left(\pi^{N D}-\pi^{D}\right)}{\partial a}>0
$$

Thus, there is disclosure for a smaller set of disclosure costs as $a$ increases.

Suppose, next, that $P^{D} \geq P^{N D}>0$. Then $\pi^{D}=\pi^{N D}$ requires that $d^{*}=H$ and $\hat{b}=b^{*}$. Furthermore,

$$
\frac{\partial\left(\pi^{N D}-\pi^{D}\right)}{\partial a}=[1-F(\hat{b})]-\left[1-F\left(b^{*}\right)\right]=0 .
$$

Finally, assume that $P^{D}>P^{N D}=0$. Then

$$
\begin{gathered}
\frac{\partial\left(\pi^{N D}-\pi^{D}\right)}{\partial a}=\frac{1-F(\hat{b})}{m(\hat{b})-\hat{b}} \pi_{0}-\left[1-F\left(b^{*}\right)\right] \\
=[1-F(\hat{b})]\left[\frac{\pi_{0}-d^{*}+P^{D}}{m(\hat{b})-\hat{b}}-1\right]
\end{gathered}
$$

But using the efficiency condition,

$$
\pi_{0}-d^{*}+P^{D}=m\left(b^{*}\right)-b^{*}
$$

Finally, $m^{\prime}<1$ and $b^{*}<\hat{b}$ implies that

$$
\frac{\partial\left(\pi^{N D}-\pi^{D}\right)}{\partial a}>0
$$

\subsection{Positioning with limited SSO competition}

The analysis so far has made the extreme assumption that there is free entry into the SSO market and delivered a number of sharp implications, including the negative relationship between sponsor-friendliness and concessions. 
A finding that $\alpha$ and $c$ co-vary negatively, though, might be attributed to the possibility that there is a limited number of SSOs for a given technology field and that user-friendly SSOs just demand more concessions. To assess the validity of this alternative theory, it is important to distinguish two types of SSO policies: ex ante rules and ex post discretionary actions. User-friendly SSOs will naturally ex post demand more concessions. ${ }^{7}$ On the other hand, our empirical analysis focuses on the ex ante rules that govern applications to the SSO. As we now show, it is much less obvious that a moreuser-friendly SSO will choose tougher requirements.

To illustrate this, we look at the case in which a fixed set of SSOs select concessions in order to attract a sponsor with known characteristic $a$ (and therefore preferred SSO $\alpha^{*}(a)$ ). For expositional simplicity, we ignore disclosure decisions and return to the basic framework of Section 3.1.

Our notion of competition can be interpreted as one among either for-profit or not-forprofit certifiers; for, in both cases, the certifier chooses $c$ so as to solve

$$
\max U(\alpha)=[1-F(b)] \pi(c)
$$

subject to

$$
a+m(b)+c \geq 0
$$

and

$$
a+b+c+\alpha \pi(c)=0 .
$$

[A not-for-profit certifier tries to attract the sponsor's business; a for-profit one charges $\left.P(\alpha)=\max \left\{U(\alpha)-\max _{\alpha^{\prime} \neq \alpha} U\left(\alpha^{\prime}\right), 0\right\}\right]$.

Proposition 4 shows that over a wide range of parameters, the concession is then increasing with sponsor-friendliness. It therefore precludes any general conclusion as to the negative co-variation between $\alpha$ and $c$. Sponsor-friendly SSOs must impose strong concessions in order to attract technologies that have weak appeal. User-friendly SSOs must demand low concessions in order to be attractive to sponsors of technologies with strong appeal.

\section{Proposition 4 (SSO positioning under imperfect SSO competition)}

\footnotetext{
${ }^{7}$ Whether they will indeed be successful in their attempt at "technology morphing" is another matter. To the extent that they delay approval, they may signal bad news to the users and so compromise the very acceptance of the standard by users even with increased concessions: see Lerner-Tirole (2004).
} 
Consider the competition between a given set of SSOs for a sponsor whose technology has appeal parameter a and preferred SSO is thus $\alpha^{*} \equiv \alpha^{*}(a)$. There exists $\underline{\alpha}<\alpha^{*}$ such that for $\alpha \geq \underline{\alpha}$, the concession c made by SSO $\alpha$ is increasing with $\alpha$. That is, the sponsor must make fewer concessions when applying to the more user-friendly SSO.

Proof: Consider a sponsor of a technology with known attractiveness $a$. Let $\alpha^{*}$ denotes his "ideal SSO," and $\left(b^{*}, c^{*}\right)$ denote the corresponding cut-off and concession level:

$$
\left\{\begin{array}{l}
a+m\left(b^{*}\right)+c^{*}=0 \\
a+b^{*}+c^{*}+\alpha^{*} \pi\left(c^{*}\right)=0 \\
1+\alpha^{*} \pi^{\prime}\left(c^{*}\right)=0 .
\end{array}\right.
$$

Consider an SSO with type $\alpha \neq \alpha^{*}$. This SSO attempts to offer as high a surplus $[1-F(b)] \pi(c)$ as it can. Suppose that $\alpha>\alpha^{*}$. SSO $\alpha$ lacks credibility in the eyes of users and must make a high concession to gain sufficient credibility:

$$
c>c^{*} .
$$

To see this, suppose, to the contrary, that $c \leq c^{*}$. Then letting $b$ denote the cut-off for $(c, \alpha)$ :

$$
a+b+c+\alpha \pi(c)=0
$$

and

$$
a+m(b)+c \geq 0
$$

if the standard is to be adopted by users. And so

$$
m(b)-b \geq \alpha \pi(c)>\alpha^{*} \pi\left(c^{*}\right)=m\left(b^{*}\right)-b^{*},
$$

which, together with $m^{\prime}<1$, yields $b<b^{*}$. But then

$$
a+m(b)+c<a+m\left(b^{*}\right)+c^{*}=0,
$$

and so the standard is not adopted by users after all. Note also that for $\alpha>\alpha^{*}$, the two constraints in program (I) must be binding; otherwise, the first-order condition would yield: 


$$
\frac{\pi^{\prime}}{\pi}+\frac{f}{1-F}\left(1+\alpha \pi^{\prime}\right)=0
$$

But $\alpha>\alpha^{*}, c>c^{*}, \pi^{\prime \prime}<0$ and $1+\alpha^{*} \pi^{\prime}\left(c^{*}\right)=0$ imply that the left-hand side of (4) is strictly negative.

Similarly for $\alpha<\alpha^{*}$, but "not too small", the two constraints in program (I) must be binding. For $\alpha$ close to $\alpha^{*}$, (4) would yield $c$ far below $c^{*}$, which by continuity cannot be the solution. ${ }^{8}$

Now, when the two constraints are binding,

$$
a+m^{-1}(-a-c)+c+\alpha \pi(c)=0
$$

and so

$$
\frac{d c}{d \alpha}=\frac{\pi}{\frac{1}{m^{\prime}}-\left(1+\alpha \pi^{\prime}\right)}
$$

Now $1+\alpha \pi^{\prime}<0$ for $\alpha>\alpha^{*}$, and $\left(1+\alpha \pi^{\prime}\right)$ small for $\alpha$ smaller than, but in neighborhood of, $\alpha^{*}$. Hence $\frac{d c}{d \alpha}>0$

\section{The Sample}

We now seek to test some of the ideas developed in Lerner-Tirole (2004) and Section 3. Before we do so, however, this section describes the construction of our sample. Our empirical approach was to develop as comprehensive a sample of SSOs as possible. To do this, we compiled data ourselves and also searched the Internet for information about these organizations and their policies.

We relied on several sources to identify SSOs. In particular, we relied primarily on the list in Lemley (2002) and www.consortiuminfo.org. We also used a variety of other lists, including www.cenorm.be/isss/Consortiua/Surveyshort.htm, www.diffuse.org/fora.html, www.webstart.com/cc.standards.html, and www.marinade.ltd.uk/content/standard.html.

\footnotetext{
${ }^{8}$ To show that the highest gross sponsor payoff cannot decrease discontinuously as $\alpha$ decreases, suppose that SSO $\alpha$ offers concession $c$ so that the standard is adopted if recommended by the SSO (if not, then obviously the payoff cannot decrease as it is equal to 0 ):

$$
a+b+\alpha \pi(c)=0 \text {. }
$$$$
a+m(b)+c \geq 0
$$

Now consider SSO ( $\alpha-d \alpha)$ with $d \alpha>0$. It is easy to see that for concession $c+d c$ the cutoff is $b+d b$ with

$$
d b=\pi(c) d \alpha-\alpha \pi^{\prime}(c) d c,
$$
}

and that the users still adopt as long as

$$
d c \geq-\frac{\pi(c) m^{\prime}(b) d \alpha}{1-\alpha \pi^{\prime}(c) m^{\prime}(c)} \text {. }
$$


We then coded the characteristics of the organizations based on the data collected from publicly available sources such as bylaws, charters, and websites of these bodies, as well as the authors' survey, emails, and telephone interviews. ${ }^{9}$

It should be noted that our sample mostly encompassed technologies related to the information technology, telecommunications and electronic industries. More specifically, in the ISO Catalogue, each ISO standard is listed under a technological sub-field such as "computer graphics", which is in turn under a technological field such as "information technology and office machines." All but one of the SSOs in our sample fell into three technological fields (field number in parentheses): (31) Electronics; (33) Telecommunications, audio and video engineering; and (35) Information technology and office machines. In fact, $80 \%$ of the sample (47 out of 59) fall exclusively in these fields.

Table 1 provides an initial overview of the sample. It lists the names of the organizations, their websites, and some additional information:

- Whether the organization has a policy covering patents.

- The rules regarding the licensing of patents by the SSO. In particular, we highlight whether the SSO required sponsors to commit to license this intellectual property on RAND terms, on a royalty-free basis, and two less-common variants: provisions that the sponsors assign their intellectual property to the SSO and that the SSO can compel licensing of the sponsors' patents.

- Whether sponsors must commit to abide by a formal dispute-resolution process.

- Whether there are requirements to disclose relevant patents (and in some cases, applications) before the selection of the standard.

\section{The Analysis}

We next present the analysis. First, we discuss the proxies that we have developed for $\mathrm{c}$ and $\alpha$. We then explore their relationship. We also consider the relationships between $\alpha$ and disclosure requirements and the maturity of the technology.

\subsection{The relationship between user-friendliness and concessions}

Table 2 summarizes the elements of the two indexes. The first seeks to capture the extent to which the SSO is oriented to users or sponsors:

- The nature of the organization. Special interest groups (SIGs) are frequently observed to have a greater orientation to sponsors than other organizations. The membership of these groups is frequently confined to intellectual property rights

\footnotetext{
${ }^{9}$ We created a survey website in June 2003. It is available at http://cess.nyu.edu/hfc/sso. We thank ISO for allowing us to base our survey on the ISO classification. The databases we used included those of Gale and ILI Infobase.
} 
holders. ${ }^{10}$ Moreover, SIGs' mandates frequently also include the marketing of these standards rather than just a dispassionate endorsement. The contrast is most sharp between SIGs and standards development organizations (SDOs) like the Institute of Electrical and Electronics Engineers. An SIG has a narrower interest than an SDO. Also, the specifications of an SIG are more likely to come from a single member, while SDOs build standards based on the contributions of various members. ${ }^{11}$

- The nature of the membership. Some SSOs have individual members, while others are confined to corporations. (Yet others involve additional parties, such as academic institutions and government agencies. ${ }^{12}$ ) We regard SSOs with allcorporate membership as higher-alpha organizations. ${ }^{13}$

- The nature of the voting rules. ${ }^{14}$ In interviews with a number of practitioners, the importance of voting rules was highlighted. The SSOs that required standards to be approved by consensus or with a super-majority were seen as being much less prone to endorse a sponsor than those that made decisions based on majority voting. ${ }^{15}$

- The age of the organization. Numerous observers (e.g., Cargill and Bolin (2004)) have observed that the standard-setting process has become increasingly

\footnotetext{
${ }^{10}$ In an illustrative e-mail, one informant writes that, "the working groups of our organization are comprised of members from many of the large industry leaders - therefore many of the companies that have an interest in IP protection are already stakeholders."

${ }^{11}$ It should be noted that there is also a third class of organization. Fora, inasmuch as the organizations are involved in the standard-setting process, are frequently seen as a middle ground. As a platform for the exchange of information, members of fora facilitate, accelerate, and promote the general interoperability of products in an industry. Fora work with other SSOs to develop standards and improve the usability of standards by preparing implementation guidelines as recommendations to members on the usage of a standard. While the organizations often seek to make use of existing standards whenever possible, they may also create its own standards or specifications. Fora thus can be seen as both complements to and substitutes of other SSOs.

${ }^{12}$ More than half of the organizations (57\%) consist of corporations only. $8 \%$ consist of both individuals and corporations, and $25 \%$ consist of corporations and others. One organization consists of all three types of members. Almost all organizations (92\%) have corporate members.
}

${ }^{13}$ These results continue to hold when we include organizations whose members are exclusively governmental bodies (which might be prone to pressure from national corporations) with the all-corporate firms.

${ }^{14}$ The major sources of information here are the charters and bylaws on the websites of the organizations, and the survey. Sometimes, there is no specific decision process pertaining to standard setting. In that case, we assumed that the publicly available decision process, which pertains to general decisions, encompasses standard setting decisions also. If the organizations answered the voting rule question in our survey, the answers were used to compile the data. Otherwise, we compiled the data ourselves by reading the charters and bylaws of these organizations; we created a summary for each of these organizations. The summaries are archived at http://cess.nyu.edu/hfc/sso/decisionprocess.zip.

${ }^{15} 34 \%$ and $27 \%$ of organizations use majority voting rules and super-majority to approve standards, respectively. $13 \%$ of organizations use consensus. There is no information for the remaining $25 \%$ of organizations. 
politicized over time. These observers have attributed this trend to the growing involvement of lawyers and business development personnel in an activity that had been previously dominated by engineers. (See Simcoe (2003) for empirical support of this claim.) While many established organizations have adjusted their rules to accommodate the interests of the sponsors, these changes have frequently been slow. Discussions suggest that rules have been slanted in a more prosponsor direction most dramatically in the more recently established SSOs. (These newer organizations have lacked the institutional traditions that have served to slow the pace of change in older groups. ${ }^{16}$ ) We expect that the SSOs established after the median date in the sample (1995) will have higher alpha.

It is difficult to assign a relative importance to these four elements. We thus simply-in an admittedly imperfect approximation-sum these four dummies, and create an alpha score between zero and four. In diagnostic regressions below, we also look at each element separately.

We similarly create an index of the number of concessions offered by the sponsor. We focus on the two elements identified as most critical in our discussions, the commitments regarding licensing and the allocation of residual decision-making rights: ${ }^{17}$

- Licensing restrictions. ${ }^{18}$ In a number of SSOs, firms must commit to license key intellectual property needed to implement the standard to those who request it. These commitments typically take two forms: either the firm commits to license the patents on a royalty-free basis, or else on "reasonable and non-discriminatory" (RAND) terms. While ambiguities surround exactly how binding a RAND licensing commitment is, most observers see it as a serious commitment, though clearly not as restrictive as a promise to provide royalty-free license (see Lemley (2002)). We include two dummies: one that takes on the value one if the firm must commit to provide royalty-free licenses, and one if they must commit to either RAND or royalty-free licenses. ${ }^{19}$ We include compulsory licensing and

\footnotetext{
${ }^{16}$ All of the organizations adopting the consensus rule are significantly older than the majority of organizations. Note that nearly half of the organizations in our sample were founded between 1996 and 2002 , and $73 \%$ of them are less than 15 years old.

${ }^{17}$ Organizations vary in the extent to which they disclosed historical information. While some organizations carefully archive earlier policy documents, in many cases only contemporaneous policies are available. Thus, when coding these policies, we simply focused on the policies that were in place in October 2002. We ignored proposed alterations to these policies when available in draft form, focusing instead on policies actually in place.

${ }^{18}$ These organizations typically define (a) what rules (e.g., RAND licensing requirements) govern the intellectual property covered under their rules, and (b) what the range of covered intellectual property is. Almost all organizations (96\%) include patents among the intellectual property policies covered under their rules. About half of the organizations $(45 \%)$ have policies governing trademarks, $77 \%$ of organizations include copyrights, and $39 \%$ cover other types of intellectual property rights.

${ }^{19}$ It is worth highlighting that many crucial details are often not stipulated in these contracts. The case Intel v. VIA Technologies (174 F.Supp. 2d 1038 (N.D. Cal. 2001)), for instance, revolved around the question of whether the licensing commitment entered into as part of a standard covered just the basic features of the
} 
patent assignment requirements as equivalent to royalty-free licensing for the purposes of this analysis. $^{20}$

- Residual decision rights. In many SSOs, there is no clear road map to resolving disputes. In others, however, the firms must commit to bringing their disputes before an adjudicary body of the SSO. ${ }^{21}$

Again, we create an index of concessions, which ranges from zero to two.

The final two measures reported in Table 2 relate to the extent of disclosure in the SSO. As highlighted in Section 3.2, the predictions here will be somewhat different from those for other concessions because of the adverse selection effect. We report whether the sponsors were required to disclose either patent awards or applications prior to the adoption of a standard.

Table 2 reports the results of this analysis. While not all cross-tabulations between the proxies for alpha and c are statistically significant, the basic pattern is clear: in every case, the level of $\mathrm{c}$ is higher for those with a lower proxy for alpha. When we add together the alpha dummies in the final two columns, we see in each case the difference is significant at the five-percent confidence level. For instance, for SSOs who require royalty-free licenses, the alpha score is 0.6 ; for the others, it is 1.6. For SSOs requiring binding dispute resolution, the alpha score is 0.4 ; for the others, it is again 1.6.

The results regarding the disclosure requirements are much less clear-cut. Only one of the ten cross-tabulations is significant, and that only at the ten-percent confidence level. The summed alpha scores are also not significantly different from each other.

In Table 3, we look at the correlations between the alpha and c proxies. There is a strong negative correlation between the scores, -0.53 , which is highly statistically significant. We also examine the correlation between these two scores and the individual elements of the other index. These correlations are each statistically significant, at least at the tenpercent confidence level. Once again, no significant relationship between the disclosure policies and the alpha score appears.

We next turn to regression analyses. In Table 4, we seek to explain the extent of concessions offered by an SSO, given its level of user-friendliness. (This assumption of the exogeneity of alpha is plausible if we assume free entry. As the tabulations discussed

standard or else also included various extensions. Some of the loopholes that firms have successfully exploited are cataloged in Feldman, Rees, and Townshend (2000) and Kipnis (2000).

${ }^{20}$ The majority $(63 \%)$ of organizations use RAND in the patent licensing rules. Only $9 \%$ of organizations use royalty-free rules. Even fewer organizations use assignment (2\%) and compulsory rules (2\%). We also repeat the analysis with a third dummy that takes on the value one for those SSOs that require patent assignment (which might be seen as particularly taxing). The results are little changed.

${ }^{21}$ Our data show that only $9 \%$ of organizations have a dispute resolution mechanism. It should be noted that in some cases, separate provisions govern copyright licensing, but we have not recorded these. 
below of the frequency of other SSOs in the technological sub-fields of our sample reveal, this assumption does not appear unreasonable. If it did not hold, we should probably regard this as more representative of correlation than causation.) In each case, we estimate first a basic specification, and then with (unreported) dummy variables that control for the technologies covered by the SSO. (We determine these first by checking the ILI Infobase, which classifies the standards published by the SSOs according to the ISO technological fields-a scheme used in the International Organization for Standardization's ISO Catalogue. ${ }^{22}$ For SSOs not included in the database, we ask the organizations to respond to our survey, filling out the number of standards they published in each field and sub-field. For non-responding SSOs, we make our own classification, based on information from the mission statements or elsewhere on the organizations' websites.) We employ ordered logit regressions throughout, reflecting the fact that while we expect that an organization with a c score of 2 is more restrictive than that with a score of 1 , it is difficult to say exactly how more restrictive it is.

The table reveals again that there is a strong relationship between $\mathrm{c}$ and alpha, even after we add industry controls. When we examine the individual elements of alpha, we see that while all the coefficients are negative, the two consistently significant indicators are if the standards body is an SIG and if all the members are corporations.

When we look at the three individual components of the c score in Table 5, we see that the alpha score is consistently negative in each. Moreover, each coefficient is statistically significant at least at the five-percent confidence level. When we look at the two disclosure measures, we find that not only is the alpha coefficient not statistically significant, but it takes on a different sign.

\subsection{Additional analyses}

In this section, we look at three additional predictions of our model. These relate to the relationships between disclosure requirements and licensing price, the impact of limited competition between SSOs, and the consequences of the differing maturity of standards.

First, as was discussed in Section 3 above, we also hypothesize a relationship between disclosure and price. In particular, Proposition 2 suggested that within an equilibrium, a higher licensing price was associated with more disclosure.

In Table 6, we look at the two most commonly encountered terms relating to licensing fees and their relationship with the disclosure provisions. We find that the presence of a provision mandating royalty-free licensing is negatively associated with the presence of a disclosure requirement, while RAND licensing is strongly associated with such a requirement. The pattern goes the same way in both the analysis of the disclosure of patent awards and applications, but it is much stronger in the former case.

\footnotetext{
${ }^{22}$ This is available on-line at http://www.iso.org/iso/en/CatalogueListPage.CatalogueList (accessed October 10, 2004). See also "How are ISO Standards Developed?", http://www.iso.org/iso/en/stdsdevelopment/whowhenhow/how.html, visited Aug 21, 2004.
} 
The pattern of more disclosure being associated with higher licensing rates in Table 6 is broadly consistent with the theoretical predictions above. The fact that the relationship is stronger for patent awards is also consistent with our predictions. Lemma 1 states that if the disclosure cost is high, then it is more likely that there will be pooling with no disclosure, making the relationship overall weaker. Since it is plausible to assume that the disclosure cost is higher for patent applications than for awards, this pattern is also expected.

Second, as noted above, an alternative hypothesis for the relationship between $\mathrm{c}$ and alpha is that the patterns are due to market power. It may be that some SSOs have few competitors. As a result, they are able to demand that sponsors make concessions, as well as having a much more user-orientated approach. As shown in Section 3.3, this argument, while initially plausible, does not bear up under scrutiny. As Proposition 4 showed, when there are a limited number of SSOs, it is by no means clear that the relationship between alpha and c will still hold.

We address this issue in two ways. First, we rerun the regressions in Table 4, simply adding a proxy for the market power of each SSO. The proxy we employ is the density of other SSOs in the same technological sub-field(s) as a given SSO. ${ }^{23}$ If the sponsor can turn to many other SSOs, then it is unlikely that the SSO can impose these types of requirements. We determine this measure again through the ILI Infobase, using the classification scheme in the International Organization for Standardization's ISO Catalogue. ${ }^{24}$ In general, the density of SSOs is quite high. The mean SSO has 13.9 other SSOs in its sub-field (with a median of 13.5).

We check to see whether once this control is added, the relationship between alpha and c still holds. Then, we compare the goodness-of-fit in regressions when SSOs do and do not have considerable competition.

Table 7 presents the results of the analysis. In the first four regressions, we examine the impact of adding the measure of density of other SSOs in the technological sub-fields. We find the measure has little impact: across all four regressions (and numerous unreported ones), it is not statistically or economically significant. As before, there is a strong negative association between $\mathrm{c}$ and alpha.

We then compare the goodness-of-fit in regressions using SSOs that did and did not have market power. We divide the SSOs into those where there was above and below the median number of other SSOs in their technological sub-fields. In the reported regressions (and in numerous unreported ones), the goodness-of-fit is higher when we use

\footnotetext{
${ }^{23}$ For instance, if an organization is active in sub-fields $\mathrm{A}$ and $\mathrm{B}$, and there are 3 and 4 active organizations in $A$ and $B$, respectively, then the market power index for this organization is $(3+4) * 1 / 2$.

${ }^{24}$ Of course, the sponsor may have the option to create a new SSO, a possibility that our measure can only imperfectly capture.
} 
SSOs located in sub-fields with many other organizations: the absolute t-statistics of the independent variables of interest are larger, the $\chi^{2}$-statistics are more statistically significant, and the log likelihoods are smaller. This is particularly striking in the last pair of regressions reported in Table 7. When using those SSOs with above-median density, three of four c-score elements are statistically significant; when using those below the median density, none are. This pattern is consistent with the predictions of Proposition 4.

The final analysis in Table 8 examines the relationship between the maturity of the standards in the technology where the SSO is operating and the alpha measure. We believe that the best indicator of opportunity is not the maturity of the project per se, but rather the collective state of projects in that particular technological sub-field. Over time, many of the substantial technological uncertainties about standards in a sub-field are likely to be resolved, increasing its attractiveness. If a field is less developed, it would be more difficult for technical committees to come up with standard proposals or drafts that take into account all technological implications, thus lengthening the approval time of standards in the field. Alternatively, there may be a higher option value to sponsors from delaying their decision to participate, as suggested in Farhi, et al. (2005). We thus use the maturity level of standards in a technological field as a proxy for the standard's attractiveness to users.

We compute the maturity of the technological sub-field(s) in which each standard operates as follows. Following the procedure outlined above, we assign each organization to one or more sub-fields as delineated in the ISO Catalogue. We then construct the maturity level for each of the sub-fields by summing up the maturity rank of each other standards in the sub-field and dividing the sum by the number of standards in each sub-field. We use the ISO's rating of maturity, which indicates the maturity of that standard on a scale of 0 ("preliminary stage") to 99 (standard withdrawn after being implemented). We compute the average maturity of the standards in that category. If there are no standards in a sub-field, it receives the least mature rank. If an organization spans across fields or sub-fields, we compute a simple average of the maturity levels for all relevant fields or sub-fields. ${ }^{25}$

Table 8 reports that there appears to be a positive correlation between maturity and alpha. The first panel indicates that SSOs operating in sub-fields where standards are above the median maturity tend to have a significantly higher alpha. The second panel presents an ordered logit regression, with the alpha score of the SSO as the dependent variable. Once again, a higher maturity score is significantly associated with a higher alpha, consistent with the theoretical predictions delineated above.

\section{Conclusions}

\footnotetext{
${ }^{25}$ In principle, we could have calculated a weighted average but since we do not have information for the number of standards of most of the organizations, we have not pursued this approach.
} 
Standard-setting organizations have received surprisingly little empirical scrutiny, despite their economic importance and dynamism. This paper seeks to address this omission, empirically examining a cross-section sample of nearly 60 SSOs.

We focus initially on two key testable hypotheses from Lerner-Tirole (2004). First, we expect that there is a negative relationship between the extent to which an SSO is oriented to technology sponsors and the concession level required of sponsors. In this paper, we indeed find a significant negative relationship, even when we control for industry effects. Second, we expect the sponsor-friendliness of the selected SSO to be positively associated with the quality of a standard. The data reveal a statistically significant association between sponsor-friendliness and the maturity of a technological sub-field in which the standard is located, which we suggest should be a proxy for attractiveness.

In this paper, we also derive a number of further theoretical results, which we then test. We extend the model in two ways. First, we consider requirements around disclosure. From the theoretical analysis emerges the prediction that within an equilibrium, a higher licensing price should be associated with more disclosure. Empirically, we find that the presence of a provision mandating royalty-free licensing is negatively associated with the presence of a disclosure requirement, while weaker "reasonable" licensing provisions are strongly associated with such a requirement. Second, we examine settings in which there are only a limited number of SSOs, and hence these organizations can dictate terms to technological sponsors. We show that in settings where there are only a limited number of SSOs, the relationship between concessions and user-friendliness may not hold. When we divide our sample of SSOs into those where there were above and below the median number of other SSOs in their technological sub-field, we find that the relationship between user-friendliness and concessions is considerably tighter among SSOs located in classes with many other SSOs.

This work leaves a number of questions unexplored. One of the most intriguing of these has to do with the dynamics of certification. Lerner-Tirole (2004) and the extensions discussed here present a static model in which a one-time decision is made. In the real world, SSOs and sponsors may employ more complex strategies: for instance, a sponsor may reapply to an SSO after its initial application is rejected. (Farhi, et al. (2005) presents a theoretical look at these issues.) Understanding the dynamics of the certification process represents an important empirical challenge. 


\section{References}

Besen, Stanley M., and Leland L. Johnson, 1986, Compatibility Standards, Competition and Innovation in the Broadcast Industry, Santa Monica, CA, The RAND Corporation.

Besen, Stanley M., and Garth Saloner, 1989, "The Economics of Telecommunications Standards," in Robert W. Crandall and Kenneth Flamm, editors, Changing the Rules: Technological Change, International Competition, and Regulation in Telecommunications, Washington, Brookings Institution, pp. 177-220.

Cargill, Carl, 2002, "Uncommon Commonality: A Quest for Unity in Standardization," in Sherrie Bolin, editor, The Standards Edge, Ann Arbor, Bolin Communications, pp. 2939.

Cargill, Carl, and Sherrie Bolin, 2004, "Standardization: A Failing Paradigm," Unpublished working paper, Sun Microsystems and the Bolin Group.

Farhi, Emmanuel, Josh Lerner, and Jean Tirole, 2005, "Second Chances: Certification under Uncertainty and Irreversibility," Unpublished working paper, MIT, Harvard University, and IDEI-Toulouse.

Farrell, Joseph, 1996, "Choosing the Rules for Formal Standardization," Unpublished working paper, University of California at Berkeley.

Farrell, Joseph, and Garth Saloner, 1985, "Standardization, Compatibility, and Innovation," Rand Journal of Economics, 16, 70-83.

Farrell, Joseph, and Garth Saloner, 1988, "Coordination Through Committees and Markets," Rand Journal of Economics, 19, 235-252.

Farrell, Joseph, and Garth Saloner, 1992, "Standard Setting in High-Definition Television," Brookings Papers on Economic Activity: Microeconomics, 1-93.

Feldman, Robert P., Maura L. Rees, and Brent Townshend, 2000, "The Effect of Industry Standard Setting on Patent Licensing and Enforcement," IEEE Communications, 38 (July), 112-116.

Hemenway, David, 1975, Industrywide Voluntary Product Standards, Cambridge, Ballinger Publishing Co.

Kipnis, Jason, 2000, "Beating the System: Abuses of the Standards Adoption Process," IEEE Communications, 38 (July 2000), 102-105.

Lemley, Mark A., 2002, "Intellectual Property Rights and Standard Setting Organizations," California Law Review, 90, 1889-1990. 
Lerner, Josh, and Jean Tirole, 2004, "A Model of Forum Shopping, with Special Reference to Standard Setting Organizations," Working Paper no. 10664, National Bureau of Economic Research.

Simcoe, Tim, 2003, "Committees and the Creation of Technical Standards," Unpublished working paper, University of California at Berkeley.

Sirbu, Marvin, and L. Zwimpfer, 1985, "Computer Communications Standards: The Case of X.25," IEEE Communications, 23 (March) 35-45.

Weiss, Martin, B.H., and Marvin Sirbu, 1990, "Technological Choice in Voluntary Standards Committees: An Empirical Analysis," Economics of Innovation and New Technology, 1, 111-133. 
Table 1 Sample Overview

\begin{tabular}{|c|c|c|c|c|c|c|c|c|}
\hline \multirow[b]{2}{*}{ Standard Development Organization } & \multirow[b]{2}{*}{ Address } & \multirow{2}{*}{$\begin{array}{l}\text { Patents Covered by } \\
\text { Organization Policy }\end{array}$} & \multicolumn{4}{|c|}{ External Patent Licensing Rules } & \multirow{2}{*}{$\begin{array}{c}\begin{array}{c}\text { Dispute Resolution } \\
\text { Mechanism }\end{array} \\
\end{array}$} & \multirow{2}{*}{$\begin{array}{c}\text { Disclosure } \\
\text { Requirements }\end{array}$} \\
\hline & & & RAND & Royalty Free & Assignment & Compulsory & & \\
\hline ANSI & www.ansi.org & $\mathrm{Y}$ & $\mathrm{Y}$ & $\mathrm{N}$ & $\mathrm{N}$ & $\mathrm{N}$ & $\mathrm{Y}$ & $\mathrm{Y}$ \\
\hline ATM Forum & www.atmforum.com & $\mathrm{Y}$ & $\mathrm{N}$ & $\mathrm{N}$ & $\mathrm{N}$ & $\mathrm{N}$ & $\mathrm{N}$ & $\mathrm{Y}$ \\
\hline BCDF & $\underline{\text { www.bcdforum.org }}$ & $\mathrm{Y}$ & $\mathrm{Y}$ & $\mathrm{N}$ & $\mathrm{N}$ & $\mathrm{N}$ & $\mathrm{N}$ & Y \\
\hline BioAPI & www.bioapi.org & $\mathrm{Y}$ & $\mathrm{Y}$ & $\mathrm{Y}$ & $\mathrm{N}$ & $\mathrm{N}$ & $\mathrm{N}$ & $\mathrm{Y}$ \\
\hline BPMI & www.bpmi.org & $\mathrm{Y}$ & $\mathrm{N}$ & $\mathrm{N}$ & $\mathrm{N}$ & $\mathrm{N}$ & $\mathrm{N}$ & $\mathrm{N}$ \\
\hline BSI & www.bsi-global.com & $\mathrm{Y}$ & $\mathrm{N}$ & $\mathrm{N}$ & $\mathrm{N}$ & $\mathrm{Y}$ & $\mathrm{Y}$ & $\mathrm{N}$ \\
\hline CEN & www.cenorm.be & $\mathrm{Y}$ & $\mathrm{Y}$ & $\mathrm{N}$ & $\mathrm{N}$ & $\mathrm{N}$ & $\mathrm{N}$ & $\mathrm{Y}$ \\
\hline CPExchange & www.cpexchange.org & $\mathrm{Y}$ & $\mathrm{N}$ & $\mathrm{N}$ & $\mathrm{Y}$ & $\mathrm{N}$ & $\mathrm{N}$ & $\mathrm{N}$ \\
\hline DCMI & dublincore.org & $\mathrm{N}$ & $\mathrm{N}$ & $\mathrm{N}$ & $\mathrm{N}$ & $\mathrm{N}$ & $\mathrm{N}$ & $\mathrm{N}$ \\
\hline DMTF & www.dmtf.org & $\mathrm{Y}$ & $\mathrm{Y}$ & $\mathrm{N}$ & $\mathrm{N}$ & $\mathrm{N}$ & $\mathrm{N}$ & $\mathrm{Y}$ \\
\hline DVB & www.dvb.org & $\mathrm{Y}$ & $\mathrm{Y}$ & $\mathrm{N}$ & $\mathrm{N}$ & $\mathrm{N}$ & $\mathrm{Y}$ & $\mathrm{Y}$ \\
\hline ECMA & www.ecma.ch & $\mathrm{Y}$ & $Y$ & $\mathrm{~N}$ & $\mathrm{~N}$ & $\mathrm{~N}$ & $\mathrm{~N}$ & Y \\
\hline ECTF & www.ectf.org & Y & Y & $\mathrm{N}$ & $\mathrm{N}$ & $\mathrm{N}$ & $\mathrm{N}$ & $\mathrm{Y}$ \\
\hline EDIFICE & www.edifice.org & NA & NA & NA & NA & NA & NA & NA \\
\hline ETIS & www.etis.org & $\mathrm{Y}$ & $\mathrm{Y}$ & $\mathrm{N}$ & $\mathrm{N}$ & $\mathrm{N}$ & $\mathrm{N}$ & $\mathrm{Y}$ \\
\hline ETSI & www.etsi.org & $\mathrm{Y}$ & $\mathrm{M}$ & $\mathrm{N}$ & $\mathrm{N}$ & $\mathrm{N}$ & $\mathrm{Y}$ & $\mathrm{Y}$ \\
\hline Frame Relay Forum & www.frforum.com & $\mathrm{Y}$ & $Y$ & $\mathrm{~N}$ & $\mathrm{~N}$ & $\mathrm{~N}$ & $\mathrm{~N}$ & $\mathrm{Y}$ \\
\hline GEA & www.gigabit-ethernet.org & $\mathrm{Y}$ & $\mathrm{Y}$ & $\mathrm{N}$ & $\mathrm{N}$ & $\mathrm{N}$ & $\mathrm{N}$ & $\mathrm{Y}$ \\
\hline Home Plug & www.homeplug.org & Y & $\mathrm{Y}$ & $\mathrm{N}$ & $\mathrm{N}$ & $\mathrm{N}$ & M & $\mathrm{N}$ \\
\hline Home PNA & www.homepna.org & $\mathrm{Y}$ & $\mathrm{Y}$ & $\mathrm{N}$ & $\mathrm{N}$ & $\mathrm{N}$ & $\mathrm{N}$ & $\mathrm{Y}$ \\
\hline HomeRF & www.homerf.org & Y & $Y$ & $\mathrm{~N}$ & $\mathrm{~N}$ & $\mathrm{~N}$ & $\mathrm{~N}$ & $\mathrm{~N}$ \\
\hline 120 & www.i2osig.org & $\mathrm{Y}$ & $\mathrm{N}$ & $\mathrm{Y}$ & $\mathrm{N}$ & $\mathrm{N}$ & $\mathrm{N}$ & $\mathrm{N}$ \\
\hline IEEE & www.iee.org & $\mathrm{Y}$ & $\mathrm{Y}$ & $\mathrm{N}$ & $\mathrm{N}$ & $\mathrm{N}$ & $\mathrm{N}$ & $\mathrm{Y}$ \\
\hline IETF & www.ietf.org & $\mathrm{Y}$ & $\mathrm{Y}$ & $\mathrm{N}$ & $\mathrm{N}$ & $\mathrm{N}$ & $\mathrm{N}$ & $Y$ \\
\hline IMTC & www.imtc.org & $\mathrm{Y}$ & $\mathrm{N}$ & $\mathrm{N}$ & $\mathrm{N}$ & $\mathrm{N}$ & $\mathrm{N}$ & $\mathrm{Y}$ \\
\hline Internet Home Alliance & www.internethomealliance.com & $\mathrm{Y}$ & $\mathrm{N}$ & $\mathrm{N}$ & $\mathrm{N}$ & $\mathrm{N}$ & $\mathrm{N}$ & $\mathrm{N}$ \\
\hline $\operatorname{lrDA}$ & www.irda.org & $\mathrm{Y}$ & $\mathrm{Y}$ & $\mathrm{N}$ & $\mathrm{N}$ & $\mathrm{N}$ & $\mathrm{Y}$ & $\mathrm{Y}$ \\
\hline ISO & www.iso.ch & $\mathrm{Y}$ & $\mathrm{Y}$ & $\mathrm{N}$ & $\mathrm{N}$ & $\mathrm{N}$ & $\mathrm{N}$ & $\mathrm{Y}$ \\
\hline ITU-T & www.itu.int//TU-T & $\mathrm{Y}$ & $\mathrm{Y}$ & $\mathrm{N}$ & $\mathrm{N}$ & $\mathrm{N}$ & $\mathrm{N}$ & $\mathrm{Y}$ \\
\hline MEF & www.metroethernetforum.org & $\mathrm{Y}$ & $\mathrm{Y}$ & $\mathrm{N}$ & $\mathrm{N}$ & $\mathrm{N}$ & $\mathrm{N}$ & $\mathrm{Y}$ \\
\hline MSF & www.msforum.org & $\mathrm{Y}$ & $\mathrm{Y}$ & $\mathrm{N}$ & $\mathrm{N}$ & $\mathrm{N}$ & $\mathrm{N}$ & $\mathrm{Y}$ \\
\hline MWIF & www.mwif.org & $\mathrm{Y}$ & $\mathrm{N}$ & $\mathrm{N}$ & $\mathrm{N}$ & $\mathrm{N}$ & $\mathrm{N}$ & $\mathrm{Y}$ \\
\hline NMF (Telemanagement Forum) & www.nmf.org & $\mathrm{Y}$ & $\mathrm{Y}$ & $\mathrm{N}$ & $\mathrm{N}$ & $\mathrm{N}$ & $\mathrm{N}$ & $\mathrm{Y}$ \\
\hline NPF & www.npforum.org & $\mathrm{Y}$ & $\mathrm{Y}$ & $\mathrm{N}$ & $\mathrm{N}$ & $\mathrm{N}$ & $\mathrm{N}$ & $\mathrm{Y}$ \\
\hline NSIF & www.atis.org/atis/sif/sifhom.htm & $\mathrm{Y}$ & $\mathrm{Y}$ & $\mathrm{N}$ & $\mathrm{N}$ & $\mathrm{N}$ & $\mathrm{N}$ & $\mathrm{Y}$ \\
\hline OASIS & www.oasis-open.org & $\mathrm{Y}$ & $\mathrm{N}$ & $\mathrm{N}$ & $\mathrm{N}$ & $\mathrm{N}$ & $\mathrm{N}$ & $\mathrm{N}$ \\
\hline OGC & www.opengis.org & $\mathrm{Y}$ & $\mathrm{Y}$ & $\mathrm{N}$ & $\mathrm{N}$ & $\mathrm{N}$ & M & $\mathrm{Y}$ \\
\hline OIF & www.oiforum.com & $\mathrm{Y}$ & $\mathrm{Y}$ & $\mathrm{N}$ & $\mathrm{N}$ & $\mathrm{N}$ & $\mathrm{N}$ & $\mathrm{Y}$ \\
\hline OMA & www.openmobilealliance.org & $\mathrm{Y}$ & $\mathrm{Y}$ & $\mathrm{N}$ & $\mathrm{N}$ & $\mathrm{N}$ & $\mathrm{N}$ & $\mathrm{Y}$ \\
\hline OMG & www.omg.org & $\mathrm{Y}$ & $\mathrm{Y}$ & $\mathrm{N}$ & $\mathrm{N}$ & $\mathrm{N}$ & $\mathrm{N}$ & $\mathrm{Y}$ \\
\hline Open Group & www.opengroup.org & $\mathrm{Y}$ & $\mathrm{Y}$ & $\mathrm{N}$ & $\mathrm{N}$ & $\mathrm{N}$ & $\mathrm{N}$ & $\mathrm{Y}$ \\
\hline OSDL & www.osdl.org & $\mathrm{N}$ & $\mathrm{N}$ & $\mathrm{N}$ & $\mathrm{N}$ & $\mathrm{N}$ & $\mathrm{N}$ & $\mathrm{N}$ \\
\hline OSGi & www.osgi.org & $\mathrm{Y}$ & $\mathrm{Y}$ & $\mathrm{N}$ & $\mathrm{N}$ & $\mathrm{N}$ & $\mathrm{N}$ & $\mathrm{Y}$ \\
\hline PCCA & www.pcca.org & $\mathrm{Y}$ & $\mathrm{N}$ & $\mathrm{N}$ & $\mathrm{N}$ & $\mathrm{N}$ & $\mathrm{N}$ & Y \\
\hline PCI SIG & www.pcisig.com & $\mathrm{Y}$ & $\mathrm{Y}$ & $\mathrm{N}$ & $\mathrm{N}$ & $\mathrm{N}$ & $\mathrm{N}$ & $\mathrm{Y}$ \\
\hline RDMA & www.rdmaconsortium.org & $\mathrm{Y}$ & $\mathrm{Y}$ & $\mathrm{N}$ & $\mathrm{N}$ & $\mathrm{N}$ & $\mathrm{N}$ & $\mathrm{Y}$ \\
\hline RosettaNet & www.rosettanet.org & $\mathrm{Y}$ & $\mathrm{N}$ & $\mathrm{Y}$ & $\mathrm{N}$ & $\mathrm{N}$ & $\mathrm{N}$ & $\mathrm{N}$ \\
\hline SDMI & www.sdmi.org & $\mathrm{Y}$ & $\mathrm{N}$ & $\mathrm{N}$ & $\mathrm{N}$ & $\mathrm{N}$ & $\mathrm{N}$ & $\mathrm{Y}$ \\
\hline SNIA & $\underline{\text { www.snia.org }}$ & $\mathrm{Y}$ & $\mathrm{Y}$ & $\mathrm{N}$ & $\mathrm{N}$ & $\mathrm{N}$ & $\mathrm{N}$ & $\mathrm{Y}$ \\
\hline STA & www.scsita.org & $\mathrm{Y}$ & $\mathrm{N}$ & $\mathrm{N}$ & $\mathrm{N}$ & $\mathrm{N}$ & $\mathrm{N}$ & $\mathrm{Y}$ \\
\hline TIA & www.tiaonline.org/standards & $\mathrm{Y}$ & $\mathrm{Y}$ & $\mathrm{N}$ & $\mathrm{N}$ & $\mathrm{N}$ & $\mathrm{N}$ & $\mathrm{Y}$ \\
\hline UPNP & www.upnp.org & $\mathrm{Y}$ & $\mathrm{Y}$ & $\mathrm{N}$ & $\mathrm{N}$ & $\mathrm{N}$ & $\mathrm{N}$ & $\mathrm{Y}$ \\
\hline W3C & www.w3.org & $\mathrm{Y}$ & $\mathrm{N}$ & $\mathrm{Y}$ & $\mathrm{N}$ & $\mathrm{N}$ & $\mathrm{N}$ & $\mathrm{Y}$ \\
\hline WAP Forum & www.wapforum.org & $\mathrm{Y}$ & $\mathrm{Y}$ & $\mathrm{N}$ & $\mathrm{N}$ & $\mathrm{N}$ & $\mathrm{N}$ & $\mathrm{Y}$ \\
\hline WfMC & www.wfmc.org & $\mathrm{Y}$ & $\mathrm{N}$ & $\mathrm{Y}$ & $\mathrm{N}$ & $\mathrm{N}$ & $\mathrm{N}$ & $\mathrm{Y}$ \\
\hline Wired for Management & developer.intel.com/ial/wfm/wfmspecs.htm & $\mathrm{Y}$ & $\mathrm{N}$ & $\mathrm{Y}$ & $\mathrm{N}$ & $\mathrm{N}$ & $\mathrm{N}$ & $\mathrm{N}$ \\
\hline X.org & www.x.org & NA & NA & NA & NA & NA & NA & NA \\
\hline XIWT & www.xiwt.org & $\mathrm{Y}$ & $\mathrm{N}$ & $\mathrm{N}$ & $\mathrm{N}$ & $\mathrm{N}$ & $\mathrm{N}$ & $\mathrm{Y}$ \\
\hline XML.org & www.oasis-open.org & $\mathrm{Y}$ & $\mathrm{N}$ & $\mathrm{N}$ & $\mathrm{N}$ & $\mathrm{N}$ & $\mathrm{N}$ & $\mathrm{N}$ \\
\hline
\end{tabular}


Table 2 Chi-Squared and t-Test Analyses of the Relationship Between Alpha and c Score Elements, as well as Disclosure Measures

\begin{tabular}{|c|c|c|c|c|c|c|c|c|c|c|c|c|}
\hline & \multicolumn{10}{|c|}{ ALPHA SCORE ELEMENT (HIGHER ALPHA CHOICE IS THE LEFT COLUMN) } & \multirow{2}{*}{\multicolumn{2}{|c|}{$\begin{array}{c}\text { ALPHA SCORE (0 TO 4) } \\
\text { If element is... }\end{array}$}} \\
\hline & \multicolumn{2}{|c|}{$\begin{array}{l}\text { Is this an SIG (SIGs } \\
\text { and SSOs only)? }\end{array}$} & \multicolumn{2}{|c|}{ Is this an SIG (all)? } & \multicolumn{2}{|c|}{$\begin{array}{c}\text { All members } \\
\text { corporate? }\end{array}$} & \multicolumn{2}{|c|}{$\begin{array}{c}\text { Decisions made } \\
\text { by majority rule? }\end{array}$} & \multicolumn{2}{|c|}{$\begin{array}{c}\text { Younger } \\
\text { organization? }\end{array}$} & & \\
\hline & Yes & No & Yes & No & Yes & No & Yes & No & Yes & No & Yes & No \\
\hline \multicolumn{13}{|l|}{ c Score Elements } \\
\hline Royalty free licensing? & $10 \%$ & $14 \%$ & $10 \%$ & $13 \%$ & $0 \%$ & $24 \%$ *** & $5 \%$ & $16 \%$ & $7 \%$ & $17 \%$ & 0.6 & $1.6^{\star *}$ \\
\hline Royalty free or RAND licensing? & $40 \%$ & $83 \% \%^{* \star *}$ & $40 \%$ & $80 \%$ *** & $59 \%$ & $87 \%$ ** & $65 \%$ & $77 \%$ & $69 \%$ & $77 \%$ & 1.3 & $2.1^{\star \star *}$ \\
\hline Binding dispute resolution? & $0 \%$ & $15 \%$ & $0 \%$ & $11 \%$ & $8 \%$ & $10 \%$ & $0 \%$ & $14 \%$ & $0 \%$ & $18 \%$ ** & 0.4 & $1.6^{\star *}$ \\
\hline \multicolumn{13}{|l|}{ Disclosure Measures } \\
\hline Is patent disclosure required? & $60 \%$ & $80 \%$ & $60 \%$ & $81 \%$ & $75 \%$ & $79 \%$ & $79 \%$ & $76 \%$ & $68 \%$ & $86 \%{ }^{*}$ & 1.4 & 1.9 \\
\hline Is application disclosure required? & $20 \%$ & $26 \%$ & $20 \%$ & $24 \%$ & $26 \%$ & $21 \%$ & $32 \%$ & $19 \%$ & $8 \%$ & $30 \%$ & 1.5 & 1.5 \\
\hline
\end{tabular}

$* * *$ denotes significant at the $1 \%$ confidence level; **, $5 \% ; *, 10 \%$.

Table 3 Correlation Analysis between Alpha and c Scores and their Elements, as well as Disclosure Measures

\begin{tabular}{|c|c|c|c|c|c|c|c|c|c|c|}
\hline & \multicolumn{2}{|c|}{ Alpha score (0 to 4) } & \multicolumn{2}{|c|}{ Is this an SIG? } & \multicolumn{2}{|c|}{ All members corporate? } & \multicolumn{2}{|c|}{ Decisions made by majority rule? } & \multicolumn{2}{|c|}{ Younger organization? } \\
\hline & Coefficient & p-Value & Coefficient & p-Value & Coefficient & p-Value & Coefficient & p-Value & Coefficient & p-Value \\
\hline c Score (0 to 3) & -0.53 & 0.000 & -0.32 & 0.018 & -0.43 & 0.001 & -0.25 & 0.071 & -0.27 & 0.050 \\
\hline Royalty free licensing? & -0.31 & 0.017 & & & & & & & & \\
\hline Royalty free or RAND licensing? & -0.36 & 0.005 & & & & & & & & \\
\hline Binding dispute resolution? & -0.31 & 0.023 & & & & & & & & \\
\hline Is patent award disclosure required? & -0.18 & 0.190 & & & & & & & & \\
\hline Is patent application disclosure required? & 0.01 & 0.987 & & & & & & & & \\
\hline
\end{tabular}


Table 4 Ordered Logit Regression Analysis of c Score, with Alpha Score and its Elements as Explanatory Variables

Dependent Variable: c Score

$\begin{array}{lrr}\text { Alpha score } & -1.13 & -1.36 \\ & {[0.30]^{* * *}} & {[0.35]^{* * *}}\end{array}$

Is this an SIG?

Are all members corporate?

Decisions made by majority rule?

Younger organization?

$$
35]^{* * * *}
$$

$$
\text { Younger organization? }
$$

Dummies for technology included?

$\mathrm{N}$

Chi-Squared Statistic

p-Value

Log Likelihood

Number of Observations

$\begin{array}{rr}\mathrm{N} & \mathrm{Y} \\ & \\ 17.41 & 23.89 \\ 0.000 & 0.000 \\ -47.67 & -44.43 \\ 55 & 55\end{array}$

$\begin{array}{rr}-1.85 & -2.04 \\ {[0.81]^{* *}} & {[0.83]^{* *}} \\ -1.71 & -1.79 \\ {[0.67]^{* *}} & {[0.70]^{* * *}} \\ -0.74 & -0.92 \\ {[0.62]} & {[0.64]} \\ -0.66 & -1.09 \\ {[0.60]} & {[0.65]^{*}} \\ & \\ \mathrm{~N} & \mathrm{Y} \\ & \\ 19.99 & 25.73 \\ 0.000 & 0.000 \\ -46.38 & -43.51 \\ 55 & 55 \\ \end{array}$

$\mathrm{t}$-Statistics in brackets.

*** denotes significant at the $1 \%$ confidence level; **, $5 \% ; *, 10 \%$. 
Table 5 Logit Regression Analysis of Elements of c Score and Disclosure Elements, with Alpha Score as Explanatory Variable

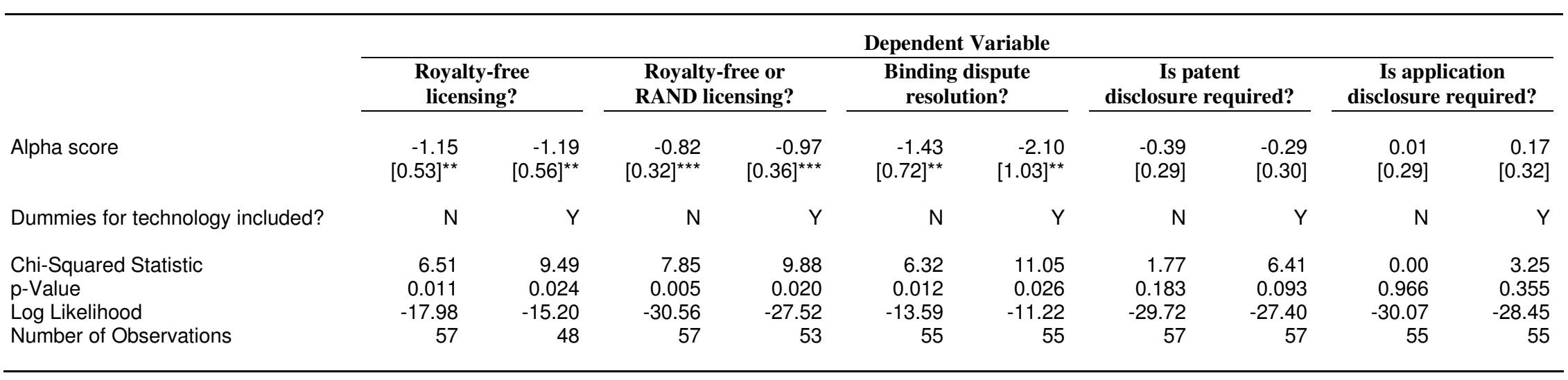

$\mathrm{t}$-Statistics in brackets.

*** denotes significant at the $1 \%$ confidence level; **, $5 \%$; *, $10 \%$. 
Table 6 Chi-Squared Analyses of c Score Elements Regarding Price and Disclosure Measures

\begin{tabular}{lcccccc}
\hline & \multicolumn{2}{c}{$\begin{array}{c}\text { Is award } \\
\text { disclosure required? }\end{array}$} & & \multicolumn{2}{c}{$\begin{array}{c}\text { Is application } \\
\text { disclosure required? }\end{array}$} \\
\cline { 2 - 3 } \cline { 5 - 6 } & \multicolumn{2}{c}{ Yes } & No & & Yes & No \\
\hline Royalty-free licensing? & $5 \%$ & $38 \%^{* * *}$ & & $0 \%$ & $17 \%$ \\
RAND licensing? & $77 \%$ & $15 \%^{* *}$ & & $85 \%$ & $57 \%^{*}$ \\
\hline
\end{tabular}

$* * *$ denotes significant at the $1 \%$ confidence level; **, $5 \% ; *, 10 \%$. 
Table 7 Ordered Logit Regression Analysis of c Score, with Market Power Proxy

\begin{tabular}{|c|c|c|c|c|c|c|c|c|}
\hline & \multicolumn{8}{|c|}{ Dependent Variable: $\mathrm{c}$ Score } \\
\hline & \multicolumn{4}{|c|}{ Using Entire Sample } & \multicolumn{4}{|c|}{ Dividing Sample into Above and Below Median SSO Density } \\
\hline & & & & & Above & Below & Above & Below \\
\hline Alpha score & $\begin{array}{r}-1.12 \\
{[0.30]^{\star * \star}}\end{array}$ & $\begin{array}{r}-1.35 \\
{[0.35]^{\star \star \star}}\end{array}$ & & & $\begin{array}{r}-1.55 \\
{[0.56]^{* \star}}\end{array}$ & $\begin{array}{r}-1.32 \\
{[0.54]^{\star *}}\end{array}$ & & \\
\hline Is this an SIG? & & & $\begin{array}{r}-1.84 \\
{[0.81]^{\star \star}}\end{array}$ & $\begin{array}{r}-2.08 \\
{[0.83]^{\star *}}\end{array}$ & & & $\begin{array}{r}-2.15 \\
{[1.11]^{\star}}\end{array}$ & $\begin{array}{r}-35.79 \\
{[229.07]}\end{array}$ \\
\hline Are all members corporate? & & & $\begin{array}{r}-1.74 \\
{[0.68]^{\star \star \star}}\end{array}$ & $\begin{array}{r}-1.83 \\
{[0.71]^{\star \star \star}}\end{array}$ & & & $\begin{array}{r}-2.38 \\
{[1.13]^{* *}}\end{array}$ & $\begin{array}{r}-1.64 \\
{[1.12]}\end{array}$ \\
\hline Decisions made by majority rule? & & & $\begin{array}{r}-0.69 \\
{[0.62]}\end{array}$ & $\begin{array}{r}-0.82 \\
{[0.66]}\end{array}$ & & & $\begin{array}{r}-0.37 \\
{[0.99]}\end{array}$ & $\begin{array}{r}-1.45 \\
{[1.23]}\end{array}$ \\
\hline Younger organization? & & & $\begin{array}{c}-0.61 \\
{[0.61]}\end{array}$ & $\begin{array}{l}-1.05 \\
{[0.65]}\end{array}$ & & & $\begin{array}{r}-2.09 \\
{[1.07]^{*}}\end{array}$ & $\begin{array}{r}-0.60 \\
{[0.94]}\end{array}$ \\
\hline Density of other SSOs & $\begin{array}{c}-0.02 \\
{[0.06]}\end{array}$ & $\begin{array}{c}-0.01 \\
{[0.07]}\end{array}$ & $\begin{array}{c}-0.04 \\
{[0.06]}\end{array}$ & $\begin{array}{r}-0.04 \\
{[0.07]}\end{array}$ & & & & \\
\hline Dummies for technology included? & $\mathrm{N}$ & Y & $\mathrm{N}$ & Y & Y & $\mathrm{Y}$ & Y & Y \\
\hline Chi-Squared Statistic & 17.53 & 23.95 & 20.36 & 26.07 & 13.56 & 9.84 & 15.69 & 12.91 \\
\hline$p$-Value & 0.000 & 0.000 & 0.001 & 0.001 & 0.001 & 0.043 & 0.008 & 0.074 \\
\hline Log Likelihood & -47.61 & -44.41 & -46.20 & -43.35 & -18.91 & -24.04 & -17.85 & -22.51 \\
\hline Number of Observations & 55 & 55 & 55 & 55 & 29 & 26 & 29 & 26 \\
\hline
\end{tabular}

$\mathrm{t}$-Statistics in brackets.

*** denotes significant at the $1 \%$ confidence level; **, $5 \% ; *, 10 \%$. 
Table 8 t-Test and Ordered Logit Regression Analysis of Alpha Score, with Maturity Proxy as Explanatory Variable

\begin{tabular}{lc} 
Alpha if mature & 1.7 \\
Alpha if not mature & 1.1 \\
t-Statistic & 1.92 \\
p-Value & 0.060 \\
& \\
& $\begin{array}{c}\text { Dependent Variable: } \\
\text { Alpha Score }\end{array}$ \\
\cline { 2 - 2 } & -1.00 \\
Mature technology & {$[0.54]^{*}$} \\
& 3.45 \\
Chi-Squared Statistic & 0.063 \\
p-Value & -81.88 \\
Log Likelihood & 58 \\
Number of Observations &
\end{tabular}

$\mathrm{t}$-Statistics in brackets.

$* * *$ denotes significant at the $1 \%$ confidence level; **, $5 \% ; *, 10 \%$. 